\title{
Functional Food Complementary to Medicine
}

\author{
Mohammad Khaled* \\ Professor Emeritus of Nutrition Sciences, USA
}

*Corresponding author: Mohammad Khaled, Professor Emeritus of Nutrition Sciences, University of Alabama at Birmingham,

Medical Center, Alabama, USA

\begin{tabular}{|c|c|}
\hline ARTICLE INFO & ABSTRACT \\
\hline $\begin{array}{l}\text { Received: March 05, } 2019 \\
\text { Published: March 18, } 2019\end{array}$ & \multirow{2}{*}{$\begin{array}{l}\text { Importance of an adequate Functional Food and its efficacies as complementary/ad- } \\
\text { junctive to medicine are described succinctly in this mini review. This Functional Food } \\
\text { not only capable of preventing postprandial inflammation, but also has proven to be ef- } \\
\text { fective in controlling blood sugar and diabetic peripheral neuropathies in synergy with } \\
\text { metformin, without any undesirable side effects. Key Words: Functional Food, Postpran- } \\
\text { dial Inflammation and Diabetic Peripheral Neuropathy. }\end{array}$} \\
\hline $\begin{array}{l}\text { Citation: Mohammad Khaled. Func- } \\
\text { tional Food Complementary to Med- } \\
\text { icine. Biomed J Sci \& Tech Res 16(1)- }\end{array}$ & \\
\hline 2019. BJSTR. MS.ID.002800. & $\begin{array}{l}\text { Abbreviations: RMR: Resting Metabolic Rate; GI: Glycemic Index; CVD: Cardiovascular; } \\
\text { FFM: Fat-Free Mass; DIPT: Diet-Induced Postprandial Thermogenesis; FM: Fat Mass; RQ: } \\
\text { Respiratory Quotient; FFA: Free Fatty Acid; IR: Insulin Resistance }\end{array}$ \\
\hline
\end{tabular}

\section{Introduction}

It begins with the quote of Hippocrates, the father of Western modern medicine, "Let food be thy medicine and medicine be thy food". A nutritious food is essential for maintaining good health and sustaining life, while a medicine is necessary to prevent and/ or treat an illness. When food cannot be considered as medicine, there exist possibilities for its use as complementary/adjunctive with medicine in our healthcare. In the absence of such treatment procedures in our current healthcare modalities, this mini review will try to shed some light on the potential applications of nutritious food in combination with medicine. Food value is, of course, dependent on its quality and quantity in terms of its energy and nutrient content to provide adequate nutrition and energy to improve health and wellness [1]. In fact, minerals and vitamins constitute the nutritional value while carbohydrate, protein and fat, are the sources of energy for oxidative metabolism, i.e. resting metabolic rate (RMR), also popularly known as "cost of living" [2]. About $50-60 \%$ of this energy comes from carbohydrate, supplied from three main cash crop cereals, namely wheat, rice and maize [3]. In order to make these crops most palatable to human taste they usually go through various milling processes during which the outer bran and germ portions are removed.
Such processes leave a starchy end product which has lower fiber content as well as lower content of anti- inflammatory vitamins and minerals, but with high Glycemic Index (GI) (ranging from 55 to $109 \%$ depending on the variety) [4]. Consuming processed carbohydrates (GI $>60 \%$ ), as currently widely used, is linked to obesity leading to chronic life- threatening diseases like Type 2 diabetes mellitus (T2DM) and cardiovascular (CVD) [5]. Although food quality nutritionally is virtually nonexistent, energy content, however, varies significantly between carbohydrates ( $4 \mathrm{kcal} / \mathrm{g}$ ) and fats (9 kcal/g). In early 90's, we, therefore, conducted a human study [6] on a diet composition with an isocaloric, isonitrogenous high carbohydrate (66\%) and low fat (20\%) diet (HC) versus a high fat (56\%) and low carbohydrate (30\%) diet (HF) to investigate any significant effects on human health, by measuring diet-induced postprandial thermogenesis (DIPT) and inflammation. Healthy, never-obese, postmenopausal, Caucasian female subjects $(n=12)$ participated in this study for 3 weeks each in a crossover design. Fat-free mass (FFM) and fat mass (FM) were measured by underwater weighing before and after each diet exposure. Resting metabolic rate (RMR) was assessed fasting and for five 40-minute periods over a 6 hours DIPT after ingesting $14.3 \mathrm{~kg} / \mathrm{FFM}$ of either $\mathrm{HC}$ or HF diet. 
A low respiratory quotient (RQ) is usually indicative of lipid peroxidation, an important index of inflammation, measured in this study as TBARS (Thiobarbituric Acid Reacting Substances). Lipid peroxidation due to the above three food regimens, measured two hours after consuming any one of these food categories, is illustrated in Figure 1. Both HF and HC diets are showing in this Figure a significantly higher peroxidation as compared to the normal diet, $\mathrm{HF}$ even showing higher than HC, thus indicating occurrence of Postprandial inflammation. Additionally, a higher postprandial thermogenesis due to both the HF and HC diets along with a significant elevation of free fatty acid (FFA) for HF were also observed in this study. Occurrence of postprandial inflammation in recent years has now been implicated $[7,8]$ intimately with Glucotoxicity and Lipotoxicity, initiating Insulin Resistance (IR), a hall mark of Type 2 diabetes (T2DM), leading to cardiovascular diseases (CVD). These two food-borne toxicities are, therefore, should be targeted in the management of chronic diseases, particularly like T2DM and CVD. Inflammation is, in general, well-known to play a devastating role in human health and wellness [8]. The European Consensus, therefore, developed the concept of Functional Food that should be capable of preventing the formation of postprandial inflammation and thus enhance the health beneficial effects, beyond that of basic nutrition, to prevent/cure chronic diseases [9].

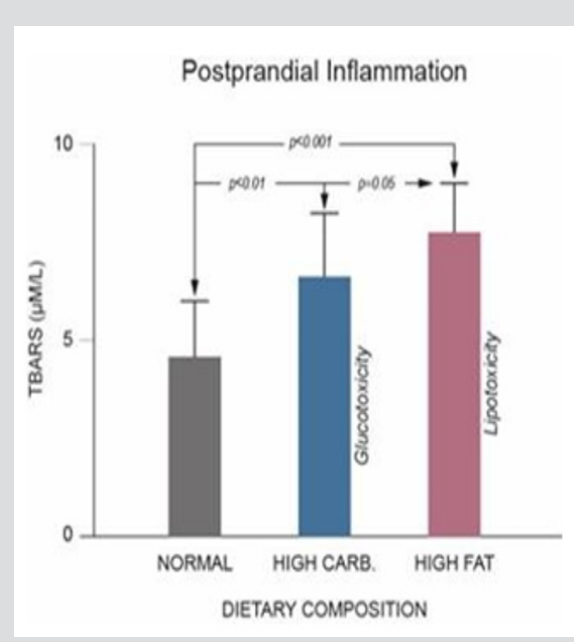

Figure 1: Lipid Peroxidation.

We have developed such a functional food (patent pending), composed of anti-inflammatory nutrients along with some nonnutrient food ingredients having medicinal values. Preliminary studies (both case-control and anecdotal) were conducted under the supervisions of an endocrinologist and/or a neurologist, to initially establish its efficacies in controlling IR by inhibiting the formation of those food-borne toxicities as cited above. This product was tested initially in an anecdotal study by supplementing to some pre-diabetics $(n=10)$, whose fasting blood sugar ranged between 100 and $126 \mathrm{mg} / \mathrm{dL}$ with higher level of insulin (hyperinsulinemia) which usually is indicative of insulin resistance (IR). It was observed, as shown in Figure 2, that after supplementing for a month only, the fasting blood sugar level was lowered from $112 \pm 10$ to $105 \pm 6$ $\mathrm{mg} / \mathrm{dL}$, al-beit not so significantly. However, the insulin level was remarkably $(\mathrm{p}<0.001)$ reduced from $23 \pm 5$ (hyperinsulinemia) to the normal level of $11 \pm 4 \mathrm{mU} / \mathrm{L}$. A randomized case-control clinical trial was, therefore, conducted on non-ambulatory T2DM patients ( $n=20, F=10)$ having uncontrolled blood sugars with concomitant diabetes-related diseases. This product showed significant effects in lowering blood sugars and as a remarkable anti-inflammatory. This study was carried out for three weeks only.

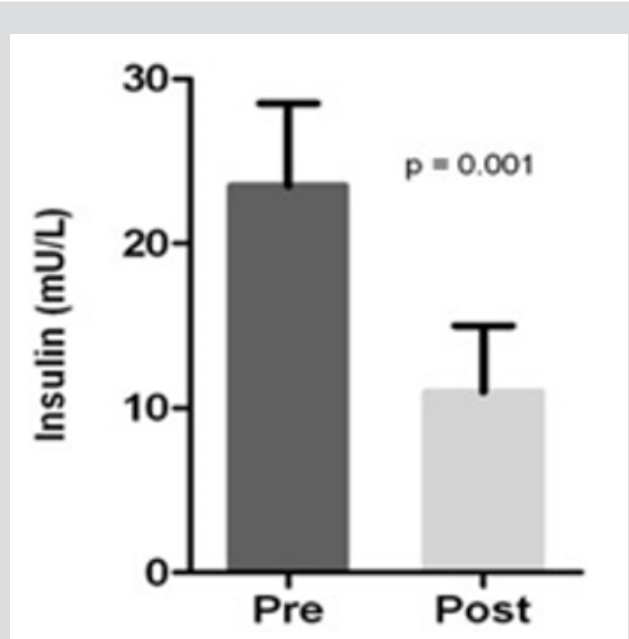

Figure 2: Fasting Insulin level before (Pre) and after (Post) taking.

Within this short period, however, some of these supplemented patients reported a significant improvement of their peripheral neuropathies, particularly in terms of their diabetic nerve pains and wounds healing. Subsequently, we conducted another anecdotal study on T2DM patients who were being treated with Metformin for over a year or so. Because:

a. Metformin is the most commonly used diabetes drug in the world and is the universal initial drug used to treat diabetes, although known to create B12 deficiency [10];

b. Diabetes is a progressive disease and eventually the vast majority of patients fail Metformin, an inexpensive generic drug, necessitating the addition of multiple other more costly anti-diabetic oral agents and then eventually insulin;

c. Based on the preliminary studies, as cited above, our Functional Food may be able to potentiate Metformin and permit longer effective glycemic control,

d. Anti-inflammatory actions of our product may prevent diabetes complications over and above the benefits of good glycemic control per se. and

e. Will certainly prevent B12 deficiency in patients on Metformin and prevent complications.

A neurologist in a Neurology/Movement Disorder Clinic, affiliated with Emory Hospital, Atlanta, performed this 
observational study. Five most deserving T2DM patients volunteered to participate and they were explained the purposes of this short study, for a month only. They were suffering from various neuropathies, particularly diabetic-nerve pains, tingling and numbness in legs and feet, including leg cramps and spasms at night, sleep disorder, anxiety and burning sensations. All of them were taking Metformin for more than a year. After giving their consents, each of them was given this Functional Food product to take 2 tablets twice a day, at breakfast and at dinner for a month only. They were asked to report to the clinic a couple of weeks after starting the product. All of them reported back as asked and indicated a great satisfaction in the relief of their illnesses, without any undesirable side effects. One of these patients, a female had an intense pain induced contortions in her feet, which had to be straightened by family member and severely lowered her quality of life, who after 2 weeks reported improvement in her leg cramps, having had one episode since beginning the treatment. The overall outcome of this short observational study warrants prospective validation of this Functional Food, which appears to hold a great promise for T2DM patients with uncontrolled blood sugar and particularly suffering from peripheral neuropathies.

\section{Conclusion}

Efforts have been made in this mini review to succinctly illustrate food value we consumed today, which is mostly devoid of important nutrients, particularly anti-inflammatory, but with high GI values. Consuming such food not only produces postprandial inflammation initiating the formation of food-borne toxicities but makes our body susceptible to many life threatening chronic diseases, like T2DM,
CVD, arthritis, cancers etc. Introduction of Functional Food appears to be capable of preventing postprandial inflammation, making it effective as complementary/adjunctive with medicine to achieve desirable treatment outcomes, thus fulfilling Hippocratic quote on food and medicine as cited earlier.

\section{References}

1. Gebhardt SE, Thomas RG (2002) USDA, Home and Garden Bulletin, p. 72.

2. (1988) Modern Nutrition in Health and Diseases, Shils AE, Young VR (Eds.). ( $7^{\text {th }}$ edn.), Lea \& Febiger, Philadelphia, pp. 533-556.

3. Cooper R (2015) Re-discovering ancient wheat varieties as functional foods. J Trad Compl Med 5(3): 138-143.

4. Soong YY, Quek RYC (2015) Glycemic potency of muffins made with wheat, rice, corn, oat and barley flours: a comparative study between in vivo and in vitro. Eup J Nutr 54(8): 1281-1285.

5. Wahlqvist ML (2001) Nutrition and diabetes in the Asia-Pacific region with reference to cardiovascular disease. Asia Pacific J Clin Nutr 10(2): 90-96.

6. Olson AK (1995) Effect of Physiologic, Caloric Intake of High Carbohydrate-Low Fat Diet VS Low Carbohydrate-High Fat Diet on DietInduced Thermogenesis in Never-Obese, Postmenopausal Females. PhD Thesis, University of Alabama at Birmingham, USA.

7. Olson AK, Khaled MA (2018) Diet-Induced Postprandial Inflammation: Consequences on Human Health. $21^{\text {st }}$ European Nutrition and Dietetic Conference, Dublin, Ireland.

8. Bell DSH, O'Keefe JH, Jellinger P (2008) Postprandial Dysmetabolism: The Missing Link between Diabetes and Cardiovascular Events? Endocr Pract 14(1): 112-124.

9. Roberfroid MB (1999) What is Beneficial for Health? The Concept of Functional Food. Food and Chem Toxicol 37: 1039-1041.

10. Rios JL, Francini F, schinella GR (2015) Natural Products for the Treatment of Type 2 Diabetes Mellitus. Planta Med 81: 975-994.

\section{ISSN: 2574-1241}

DOI: $10.26717 /$ BJSTR.2019.16.002800

Mohammad Khaled. Biomed J Sci \& Tech Res

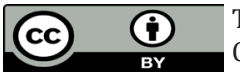

This work is licensed under Creative Commons Attribution 4.0 License

Submission Link: https://biomedres.us/submit-manuscript.php

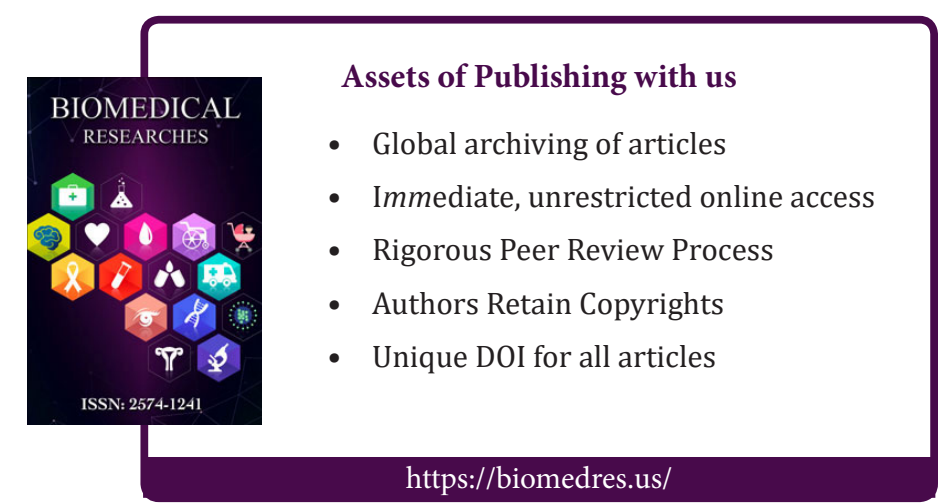

